\title{
An Ecology of Operations: Vigilance, Radar, and the Birth of the Computer Screen
}

Computer SCREENS EMERGED FROM THE problem of integrating humans, computers, and their environment in a single problem-solving system. More specifically, digital graphics and computerized visualization emerged from the problem of integrating real-time human feedback into computerized radar systems developed by the US military in the early decades of the Cold War. ${ }^{1}$ In the course of the 1950 s and 1960s tinkering engineers adapted techniques developed for visualizing enemy trajectories to somewhat less bellicose applications in computer graphics. Indeed, a wide variety of early computer-generated graphics-from John Whitney's computer-aided animations and Ivan Sutherland's Sketchpad program to early video games like Spacewar! and Tennis for Two-did little more than tweak the techniques of aerial defense into diversions like visualizing abstract patterns and intercepting, so to speak, an opponent's tennis ball. ${ }^{2}$ To borrow film historian Kyle Stine's felicitous phrasing, by folding picturing and calculation into dual aspects of a single process, these systems joined humans and calculating instruments in a single circuit of information processing. ${ }^{3}$ In fire-control systems (as mechanically aided approaches to tracking and targeting the enemy are often called), these feedback circuits often included the environment itself. Together, these elements of the system-human, instrument, environment-formed what I term an ecology of operations that distributed complex mathematical problems in recursive chains.

In the pages that follow I term this integration of visuality, calculation, territory, human problem-solving, and the human body in early information processing computational screening. At the most basic level, this term designates the productive integration of visualization technologies (that is,

A B S T R A C T This article examines the birth of interactive computer screens from enemy targeting and tracking systems (especially computerized radar) that distributed information processing in an ecology of operations among humans, computational instruments, and the environment. It proposes a concept of "computational screening" to account for the integration of visualization and information processing that gave rise to digital images. REPRESENTATIONS 147. Summer 2019 (C) The Regents of the University of California. ISSN 0734-6018, electronic ISSN 1533-855X, pages 59-95. All rights reserved. Direct requests for permission to photocopy or reproduce article content to the University of California Press at https:/ / www.ucpress.edu/journals/reprints-permissions. DOI: https://doi.org/10.1525/rep.2019.147.1.59. 
screen displays) and information processing (the screening and filtering of incoming data) that gave birth to digital graphics. Frequently, the screening of space (the flow of bodies across the membrane of a territory or through a battlefield) is also a key element of computational screening. As an analytical concept, computational screening calls attention to the history of computers as what Gilbert Simondon termed an "open machine," reliant on continuous exchange with humans and their physical environment. ${ }^{4}$ In computational screening, visual, graphical, and optical media, as well as physical space and human bodies, collaborate in the production of circuits of computation. Although computational screening took shape in the complex human-computer systems of twentieth-century fire-control, today it includes a much wider array of problems involving conditions too complex to permit problem solving by computing machines alone (that is, without human support). The processing of crunchable social data by Facebook and the monitoring of traffic patterns by the navigation app Waze, for example, involve the development of sophisticated visual interfaces that entice humans to complete information processing tasks too complex for digital instruments alone. Indeed, the actualization of computers into something approaching Alan Turing's universal machines is inconceivable without a vast array of visual interfaces that permit computers to enter into dynamic feedback loops incorporating input from users and their environments. Without the digital images enabling this circuit, the computer is little more than a fantastic automaton: that is, either an inert and preprogrammed bauble or a plaything that dwells in the imagination. ${ }^{5}$

This article reconstructs a history of computational screening as it developed from naval artillery control systems developed just after World War II through the deployment of the Semi-Automatic Ground Environment (SAGE) computerized radar defense system shortly before the 1962 Cuban Missile Crisis. This historical arc emphasizes how the demands that modern warfare placed upon vision, territory, and attention in this period produced not only a new kind of digital image but also, specifically, a new kind of interactive image: one that enlisted bodies, attention, and calculation in the production of space. As art historian Pamela Lee has incisively written, "Cold War defense strategy could itself be described as a semiotic endeavor-an attempt to decode a shadowy enemy through a raft of signs both militaristic and cultural, including 'indexical' traces registered through the new technologies of radar; anthropological analyses of Soviet, Japanese, and German attitudes to authority; and the interactive dynamics observed within the ascendant field of the behavioral sciences." ${ }^{6}$ I track one of these semiotic endeavors, the development of computational screening, an enterprise that drew on radar, computer science, psychology, moving images, physiology, geography, and other fields to establish 
a martial aesthetic that informs the attention economies of twenty-firstcentury digital cultures.

This history of computational screening and its alliance of visual interfaces with information processing reframes a much-discussed problem concerning vision and computing. Frequently, theorists of media and visual culture have argued that the computer is not a visual device. Media theorist Friedrich Kittler posited that in an age of electronic screens "visible optics must disappear into the black hole of circuits ... [because] computers, as they have existed since World War II, are not designed for image-processing at all." 7 Germanophone media theorists Wolfgang Hagen and Claus Pias echoed Kittler, resolutely declaring in their respective theoretical sallies that "there is no digital image." ${ }^{8}$ These and a host of other digital iconoclasts argue that, unlike traditional media such as photography, cinema, or painting that have a more or less determinate relationship to light, color, and spatial extension, electronic signals have neither a fixed nor an intrinsic relationship to vision. ${ }^{9}$ Often these theorists further maintain that the digital image lacks stable relationships to human bodies and space. ${ }^{10}$ For the proponents of digital iconoclasm, electronic pictures are like the afterimages that flicker into perception after the severing of an optical nerve: They may "look" like the real thing, but they are the tricks of habituation, bereft of any correspondence beyond the random flickering of electrical signals.

The roots of computer screens in fire-control, however, undermine efforts to define computational images as radically disembodied, without any relationship to optics, space, or computational processes. Under the conditions of modern warfare, maintaining the attention of jittery, easily distracted soldiers, often in monotonous conditions of inactivity punctuated by brief intervals of mind-numbing violence, was central to the computational endeavor. In fields of warfare characterized by superhuman speed, computers served as environmental technologies establishing stable ratios between bodies, machines, and space. Prolonging real-time calculations across mechanical as well as manual digits, establishing continuous communications between the electrical signals of hardware and wetware, was integral to the techniques of fire-control-so much so that methods of fire-control famously gave birth to a science of cybernetics that dissolved oppositions between mechanical computers and human users. ${ }^{11}$

As a basis for thinking about technical setups, fire-control turns analysis away from a conception of computers as self-contained and autonomous machines and toward a conception of computers as control mechanisms that distribute information flows across instruments, users, and their environments. ${ }^{12}$ Consider, for example, how Kittler's account of digital images and optics shifts when fire-control is taken as the point of departure. Taking cues from Claude E. Shannon's schematic diagram of a general 


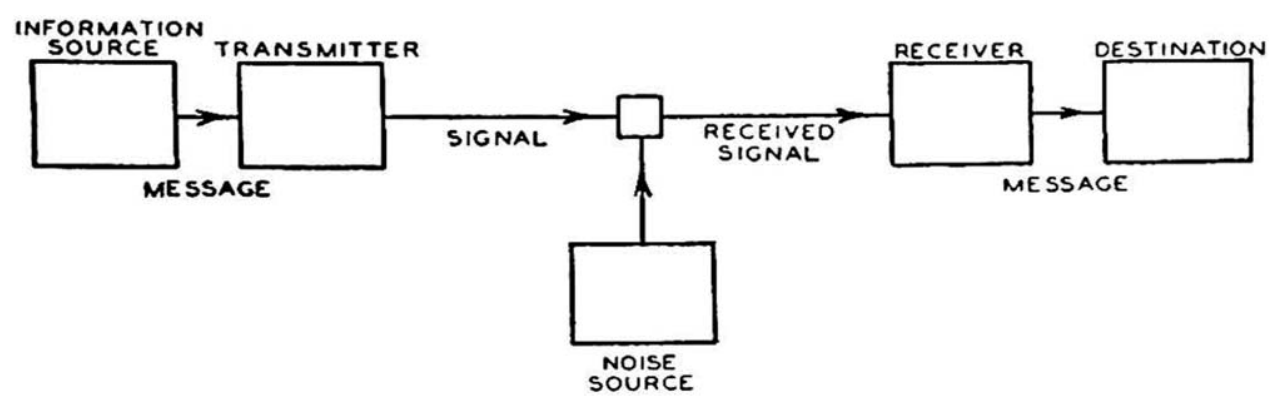

FIGURE 1. Claude E. Shannon's "schematic diagram of a communication system" interpreted by some media theorists as excluding humans from signal processing in digital systems. Source: Claude E. Shannon and Warren Weaver, The Mathematical Theory of Communication (Urbana, 1949), 5.

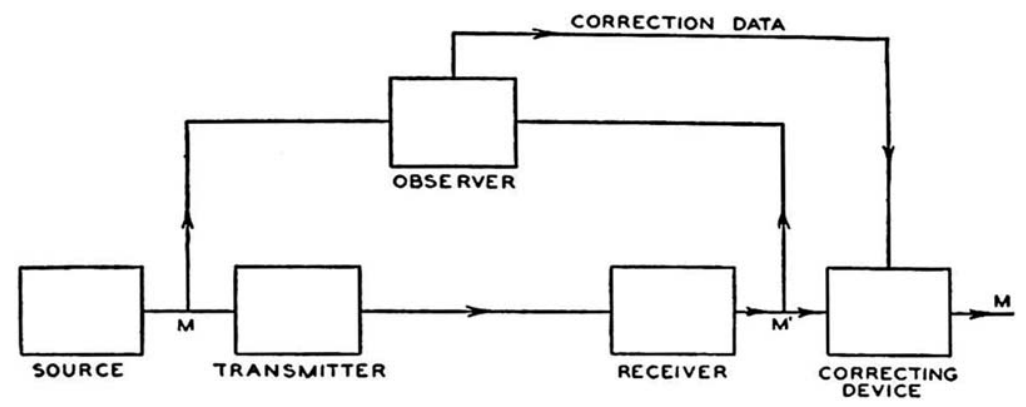

FIGURE 2. Shannon's "schematic diagram of a correction system" allowing for human or machine "observers" to process signals. This particular diagram recalls the fire-control systems Shannon studied and improved during World War II. SAGE and its computer screens grew out of these World War II systems. Source: Shannon and Weaver, The Mathematical Theory of Communication, 37.

communication system in The Mathematical Theory of Communication (fig. 1), Kittler likened electronic media to closed linear systems that excluded humans from signal processing. ${ }^{13}$ Kittler neglects to mention that in the same paper Shannon offers a second schematic of communications systems that featured an "observer" responsible for correcting data as it streamed through the communication system (fig. 2), much like the 1940s fire-control systems Shannon and his Bell Labs colleagues refined on military contract during World War II. Only by omitting this second diagram from consideration could Kittler exclude human perception from electronic systems and effectively sidestep an equally foundational history of early computing that 
included human perception within signal processing. Fire-control calls our attention to a history of information processing that, taking this second diagram as its schematic of productive relations, brings human perception to bear on the composition of digital signals. This reoriented perspective restores continuity between the screen-rich cultures of present-day digital cultures and the early decades of electronic computing.

\section{The Electronic Eye and the Radar Defense Screen}

The tensions that spurred the development of computational screening were on display in 1954 in an episode of the US television documentary program Science in Action titled "Radar Defense Screen." Broadcast from a not-yet computerized radar defense sector, it showed how an ecology of electronics, images, and bodies came together to form screening technologies. The program opened with a call to viewers to practice a new vigilance over space and time. "Today," the host explained, "our two oceans, one on either side of the country, are no longer barriers to a sudden surprise attack." 14 The television screen cut to shots of an enemy fighter plane flying overhead, followed by images of a nondescript American city turned coal black as mushroom clouds filled the screen. "Now what we saw there," warned the host, "could happen to any of us." In anticipation of such threats, the United States Air Force had developed the radar defense screen, "an electronic eye which sweeps the sky both by day and by night to prevent the arrival of any unwelcome intruder." The earnest host and his military guests took viewers on a tour of a regional radar control center where teams of soldiers scrutinized cathode-ray screens, transparent plotting boards, and regional maps. Tracking and targeting enemies demanded faithful transposition of coordinates from radio waves in the field, across electronic devices, and onto human-legible visual displays, where humans, screening out an enemy signal from the meteorological noise, transmitted data to plotting boards for extrapolation and analysis by a strictly ordered military hierarchy. A moment's inattention, a slip-up in numerical digits or Cartesian coordinates, or slight miscommunication in the chain of command could lead to fissile annihilation on American soil.

Computer graphics emerged from these kinds of efforts to calculate against catastrophic destruction. The effort to defend American frontiers in the 1950s put intense pressure on the gaps between human and machine, among the most fragile links in the vast networks of radar defense distributed along the North American coasts. This defensive situation called for faithful screening, both in terms of information processing and visual 
display (terms that proved hardly distinguishable). The first digital computer screens-displays of electronic data modulated in real time through the networked interfacing of human users and computer processing-arose from this nexus of temporal, spatial, and cognitive pressures embodied by mid-twentieth-century North American aerial defense. In it, screens and screening - that is, (1) techniques of visual display, (2) techniques of filtering signal from noise, and (3) techniques for regulating the flow of bodies to produce a specific space-converged in an information processing network that transformed visuality and territory in one fell swoop. ${ }^{15}$ The soon to be unveiled SAGE computerized radar defense system integrated radar data from its sector with computer records of preplanned flights and mapped it onto familiar cartographic displays for human interpretation (figs. 3 and 4). With the click of buttons, human operators could isolate unrecognized flight paths and dispatch Nike missiles or jet squadrons for their interception. In this process of screening, intervention took priority over representation. The screen presenting graphics to an operator did not represent information in a machine but instead took part in its production. Successful screening procedures produced continuity among image, space, body, and mathematics.

That a new computational image arose from mapping technology should come as little surprise. As Valérie November, Eduardo Camacho-Hübner, and Bruno Latour have observed, "Maps have always been calculation interfaces," and the closest precedent to the aerial maps of radar defense, the nautical chart (a maritime map), "is like a 2D slide-rule that incorporates in a precalculated format huge masses of information about angles and distances on which is overlaid in various fonts other types of information." ${ }^{16}$ Mapmaking economically condenses a vast range of calculations within the space of a flat surface, with the understanding that navigators would recognize this image as a kind of tool, a data set, whose visuality contained a series of mathematical affordances for the user to later extract and complete. Early radar displays animated mathematical affordances already present in classical maps, bringing its stable lines of force into alignment with temporality of modern warfare. Indeed, the demand for time-critical computations spread across human-machine networks was the raison d'être for these digitally generated displays; embedded within them was a temporality of emergency that called for interfaces encouraging constant vigilance. ${ }^{17}$

The technical hallmarks of the emerging electronic image, which continue to define the aesthetics of the digital image today-processual, interactive, modular, gridded, time-critical-corresponded to the temporalities of midcentury radar defense (fig. 5). The electronic image eschewed stable and indexical traces in favor of algorithmic flickers that updated instantaneously according to the time-critical operations. The aesthetics of this 


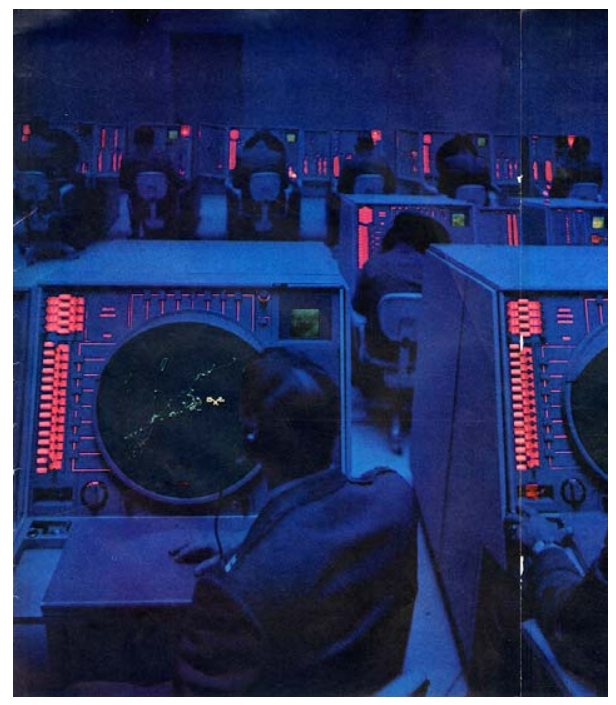

FIGURE 3. Situation displays in the SAGE air surveillance room presented real-time pictures of the air space around a particular defensive sector (e.g., New England). Source: "Pushbutton Defense for Air War," LIFE 42, no. 6 (1957): 62.

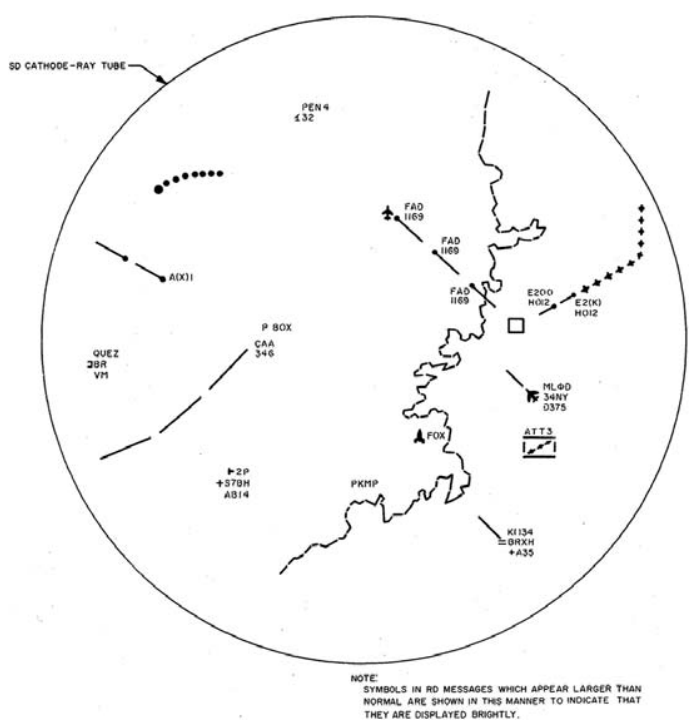

FIGURE 4. Diagram of a situation display screen depicting a coastline, planes and their flight paths, a missile and its flight path, and various cartographic characters. Source: Theory of Operation of Display System for AN/FSQ-7 Combat Direction Center and AN/FSQ-8 Combat Control Central, Volume I (Kingston, NY, 1958), 21. 


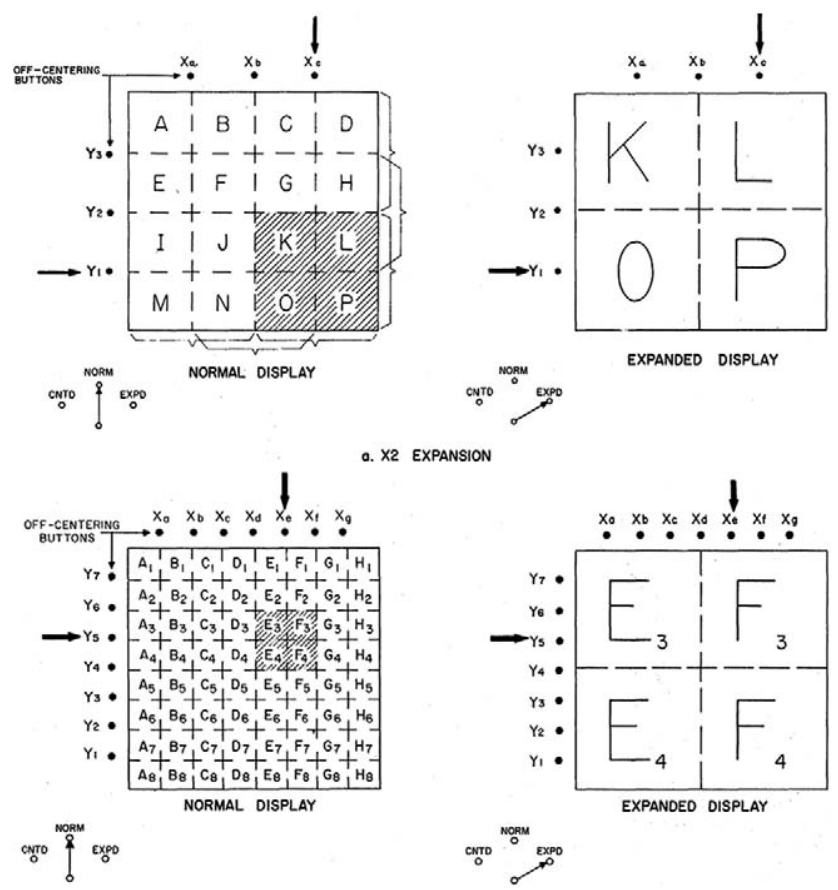

FIGURE 5. Diagram showing how segments of the situation display screen zoom in to provide more detailed display of a particular region. Source: Theory of Operation of Display System for AN/FSQ-7 Combat Direction Center and AN/FSQ-8 Combat Control Central, Volume I, 116.

image produced vigilant teams of users whose attention was focused by the glimmer of the electronic screen, their cognitions knit together by a screenscape distributed across the defensive region and among their fellow soldiers manning the radar network. Each operator's interface featured multiple screens clustering information (a bit like latter-day stackable Windows interfaces) and permitting zooming into specific quadrants or displays of key layers of information. This resulted in a dynamic interface that adapted to the crises at hand, permitting human operators to penetrate deep into the data in moments of crisis, through flickering screens responding to the dual demands of system and individual user. In this regard, both the digital image and the psychology it cultivated manifested the atmosphere of anxiety ultimately responsible for their production. By the mid-twentieth century, radiation, rockets, and atomic warfare formed a threatening trio that overwhelmed existing means of screening and territorial control. Science in Action's warning that this "could happen to any of us" announced this reconstitution of space, circa 1954, in which the 
apparatus of televisual broadcasting itself participated. ${ }^{18}$ Like radar, television converted electromagnetic waves into graphical displays to provide instantaneous pictures from remote locations. Electronic media such as radar, television, and the computer screen embodied an ambivalent technological response, an attempt to reassert national territorial integrity by means of the same technologies responsible for its dissolution. ${ }^{19}$

\section{Birth of the Computer-Generated Moving Image}

Computational screening took hold at sea. Long before the twentieth century, maritime instruments such as the astrolabe, compass, nautical chart, sextant, and chip log joined optics and image together with number and line to produce stable, navigable coordinates. ${ }^{20}$ The difficulty of controlling space in modern naval warfare, however, brought new pressures to bear on this problem. As historian of technology David Mindell has written, "Warfare at sea takes place on a battlefield with no landmarks, no terrain, no features. More akin to a magnetic field than to a farmer's field, it is characterized not by stable geography but by imaginary lines of force imposed upon an otherwise smooth and turbulent space.... Bringing these spaces under quantitative control required instruments to establish references for heading, horizon, and lines of fire." ${ }^{21}$ By the early decades of the twentieth century, the problem of two or more bodies in mutual motion in wide open sea, hurling projectiles at one another across great distances, called for the development of new technologies of vision.

In 1916 the Sperry Gyroscope Company released the Sperry Fire Control System to manufacture the stable, calculable territory demanded by modern warfare at sea. The Sperry Fire Control System and its successors shifted the task of identifying, targeting, and firing on an enemy from one or two persons and their corresponding instruments to an information processing system distributed across the ship. This setup amalgamated image, writing, number, and body within a single ecology of operations (fig. 6). One device that ensured the timely relay of calculations between the mechanical system and its human components was the Battle Tracer (fig. 7), a revolutionary computer that plotted the motions of host and enemy ships in real-time during battle. ${ }^{22}$ It consolidated a variety of data streams into an animated image produced by a graphical writer as a battle unfolded. ${ }^{23}$ Inputs from spotters above deck as well as instruments such as the ship engine combined to provide up-to-date graphical representations of the locations and bearings of the friend and enemy ships. Officers fed data from the Battle Tracer to a transmitter that supplied targeting data to the battery of guns on the decks above. 


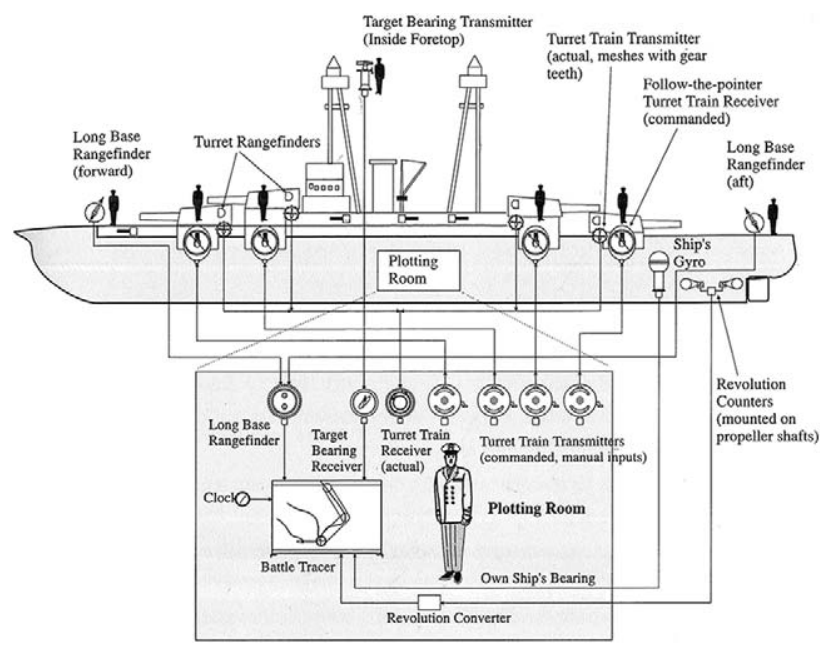

FIGURE 6. Historian

David Mindell's

diagram reconstructing the Sperry Fire Control

System and its

distribution of

targeting across the

ship and its crew.

Source: David A.

Mindell, Between

Human and Machine:

Feedback, Control, and

Computing Before

Cybernetics (Baltimore, 2002), 31.

Computational images that translated numerical representations into optical formats more easily processed by humans were what bound together the elements of the Sperry Fire Control System. Above deck a human director in a tower used monocular telescopes (fig. 8) to track an enemy ship's range, bearing, and speed; manual and automatic instruments converted these observations into electrical impulses transmitted to gunnery officers below deck; these officers cross-referenced the data with printed firing tables and, equipped with compass and protractor, translated this data into a cartographic form that determined elevation and bearing for use by artillery to target an enemy vessel. Humans entered the solution into an electromechanical device that transmitted the information to receivers in the gun turret, which then provided visual arrows indicating where the gun should be aimed. Back in the towers, timers that predicted the flight time

Figure 7. The Battle Tracer mounted on a table. Source: The Sperry Fire Control System (Brooklyn, NY, 1916). Hagley Museum and Library, Wilmington, Delaware.

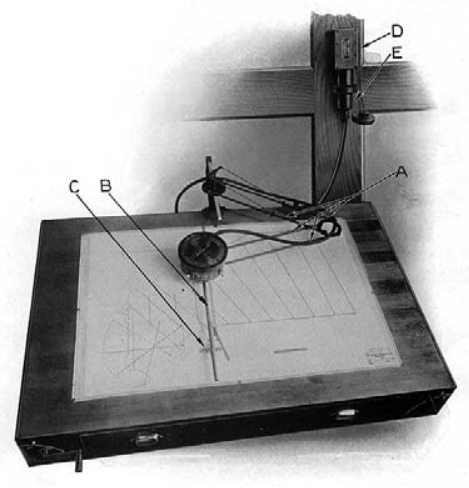


FIGURE 8. Directorscope in the Sperry Fire Control System that would have been manned by a human director. It was equipped with a monoscope, and it electrically transmitted coordinates to officers below deck. Source: Navy Ordnance Activities: World War, 1917-1918 (Washington, DC, 1920), 158-63.

of munitions would ring at the precise moment when the fired artillery landed, thus aiding human spotters in gathering data for targeting corrections and setting the entire cycle of data processing back into motion. In this fire-control system, data traveled in loops, converting from biological through numerical to graphical media moment by moment, rapidly shifting from analog to digital forms, and across optical and aural outputs.

The Sperry Fire Control System fashioned users, instruments, and space as complementary elements within a single ecology of operations. The circulating images of the Battle Tracer (and its digital descendants) integrated humans, machines, and space into a system of recursive feedback within a simultaneously real, yet virtual, territory. The Battle Tracer was both a picture of existing space and a repertoire of latent actions for producing this contested territory: Should the ship pivot starboard in pursuit of the enemy? Should it beat a hasty retreat? Should it hold its current course and fire on the foe? Where, for that matter, might the foe be found? By condensing signals from across the ship into a graphical output, the Battle Tracer diagrammed potential responses to these queries. The answer chosen by an officer and entered into the transmitters set in motion signals for the production of new data series and new environments. From the urgent needs of modern maritime warfare, computational screening had been born.

\section{Radar as Nested \\ Screening Operations}

In 1932 Stanley Baldwin of the British House of Commons declared plainly, "It is well for the man in the street to realize that there is no power on earth that can protect him from being bombed." 24 This realization put into motion the British invention of radar, its rapid improvement by the Allies 
during World War II, and, ultimately, a new era of electronic images. The imperative for new screening technologies sprang from the rapidly diminishing efficacy of the English Channel as a natural defense against enemy intrusion in an age of rapidly augmenting aerial powers and munitions. During World War I the British Isles suffered a stunning 103 air raids at a cost of 1,413 lives, and the British military command expected those numbers to be dwarfed in wars to come. ${ }^{25}$ In the mid 1930s, British scientists devised a solution to the emerging spatiotemporal ratios of warfare when they determined that precisely attuned radio relay systems distributed along the coastline could provide a kind of electromagnetic screen that offered the minimum warning necessary to scramble a counter-offense. Engineers abbreviated this system of radio detection and ranging "radar."

Radar operates according to a nested series of screening operations. The first screening typically happens at the level of the environment itself: radar transformed hundreds of miles of open space into a surface for the reflection of radio waves traveling at a rate of 186,000 miles per second before reflecting back to a precisely tuned receiver. Airplanes and other objects in open space became screens that, like an inverted X-ray photograph, return waves to their point of emission. In the typical radar setup of the 1940s, received signals were projected by an electron beam aimed at the flat end of a cathode-ray tube (CRT), which provided a rudimentary screen for human operators to interpret. The human operator acted as an additional screen responsible for filtering out signal from noise (Shannon's "observer"), that is, for distinguishing the phantomlike blip of an approaching enemy from clouds, flocks of birds, irregular surfaces, and other obstructions that rendered the returning signal difficult to read. Once operators identified an enemy, they worked with the commanding officers and teams in the field to enforce a defensive screening perimeter that intercepted the enemy with planes and artillery.

Radar of the 1940s devised a series of dynamic electronic displays to ensure accurate assignment of enemy locations. The earliest radar display format, the A-Scope (fig. 9, Type A), featured a single line that scanned from left to right along the horizontal axis. As successive waves of rays reflected, they displayed as jagged "pips" erupting into the vertical axis of the screen, thereby contouring distributions in real space through the temporal patterning of rays translated by the scanning beam into a graphical form. Depending on the strength and profile of a pip, an experienced reader could distinguish various objects-for example, birds, planes, or buildings—and their elevation. Another display, the J-Scope, stretched the timeline around the circumference of the oscilloscope, thus doubling the length of the timeline and allowing for a more exact measurement of distance (fig. 9, Type J). A third type of display developed late in the war, the 


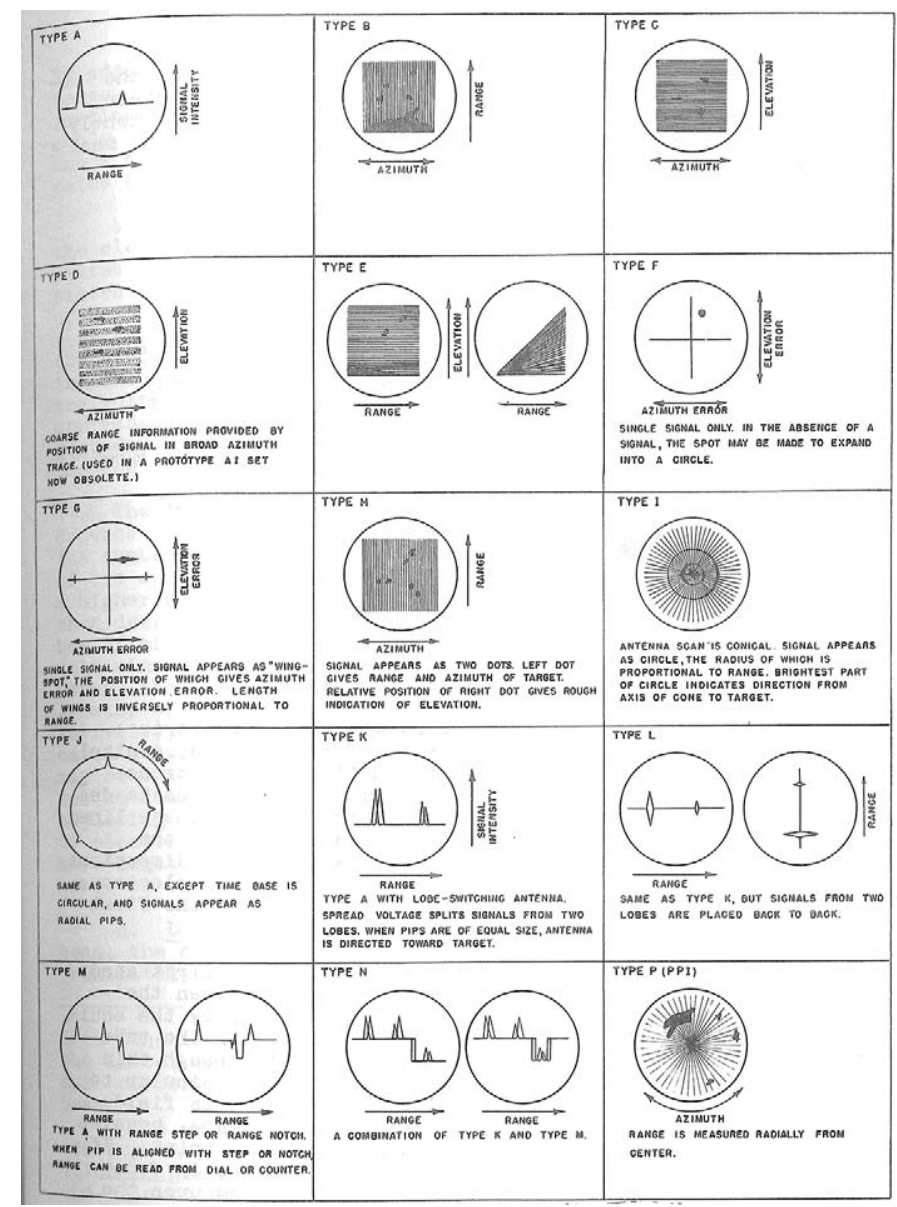

FIGURE 9. Fifteen variations on radar data display, each varying the display according to a particular conception of how best to distribute computation across human and nonhuman elements. The simplest format, an A-Scope (Type A), displayed range on the $x$ axis and the intensity of reflected waves on the $y$ axis. $\mathrm{J}$-Scopes (Type J) stretched the display of range around the circumference of the screen. Over time Type $\mathrm{P}$, the plan position indicator (PPI), which represented relations in a manner that resembled traditional two-dimensional maps, became more widespread. Source: Radar School of the Massachusetts Institute of Technology, Principles of Radar (New York, 1946), 3-3.

Plan Position Indicator or "PPI," executed 360-degree rotating scans of the surrounding milieu and displayed the results in a manner reminiscent of more traditional two-dimensional cartographic renderings (fig. 9, Type P). In all these setups, the oscilloscope functioned not just as a surface for 
representations but also as a short-term storage device for electronically calculated data. The short-term duration of these data allowed another element in the calculating apparatus, namely the human operator, to access, modify, and relate the data of other elements in the system (human or nonhuman) responsible for targeting.

The displays employed by a particular radar screen corresponded to a specific local task as well as an ecological distribution of operations across environment, system, instruments, and teams of human users. This ecology invested images with a mixture of multimedial and interactive capacities: the value of an image related to its ability to correlate with other kinds of images and data points. Take, for example, the celebrated SCR-584 radio set. Two operators would sit at a console (fig. 10) that included two $\mathrm{J}$-Scopes, one measuring a coarse $(32,000$ yards) range of objects and the other, a fine (2,000 yards) range, to allow for increasingly precise visualization as the enemy approached. A third oscilloscope represented the entire surrounding region in a PPI format. Supplementary handwheels controlled antenna position and azimuth and, depending on the setup of that particular 584, permitted the operators to isolate distinct pips on the J-Scopes for automatic tracking. Early versions of the SCR-584 relied on human officers

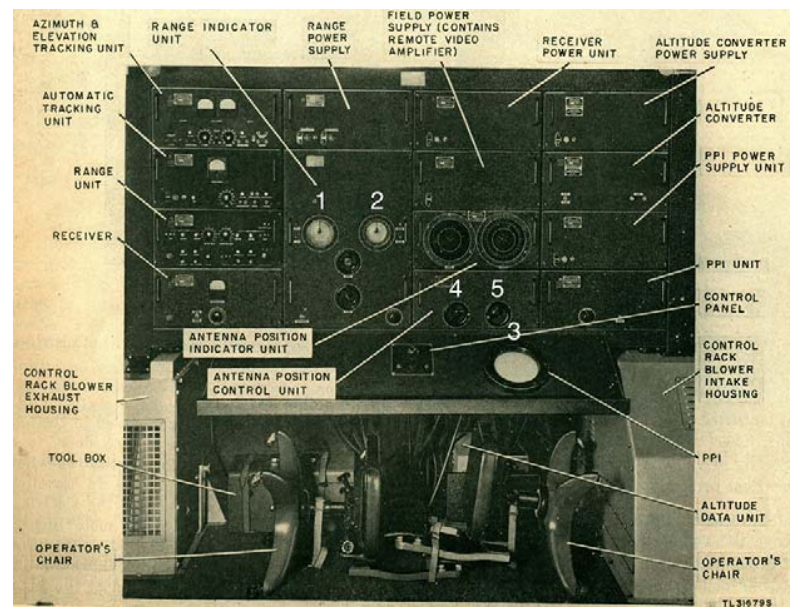

FIGURE 10. Main operating console for the SCR-584. Image modified by author to number the coarse range J-Scope (1), the fine range J-Scope (2), the PPI scope (3), and the antenna hand wheels for controlling antenna elevation (4) and azimuth (5). Source: US War Department, Radio Sets SCR-584-A and SCR 584-B Service Manual: Theory, Troubleshooting, and Repair. Technical Manual II-1524 (Washington, DC, 1946). Yale University Libraries, New Haven, CT. 


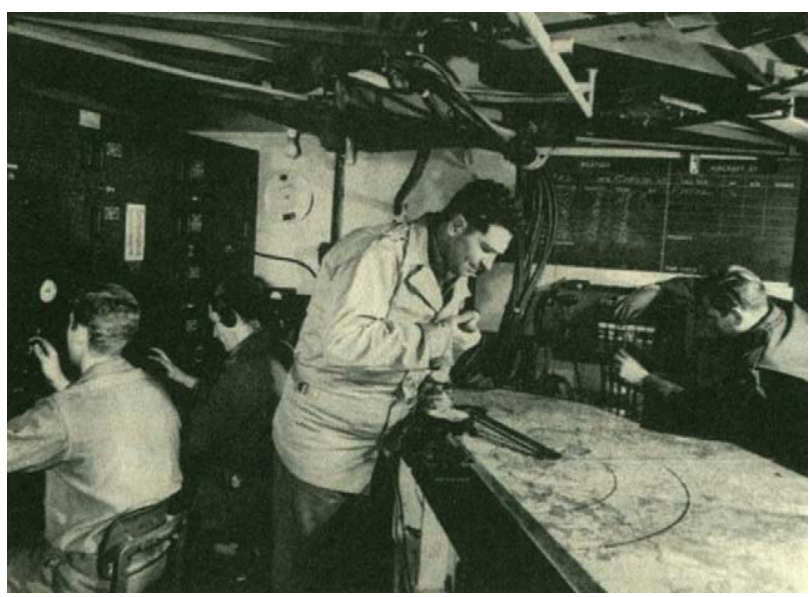

FIGURE 11. Interior of SCR-584 trailer featuring radar operators and officer at the manual plotting board. Source: David A. Mindell, Between Human and Machine: Feedback, Control, and Computing Before Cybernetics (Baltimore, 2002), 253.

who plotted observations in graphical form and extrapolated trajectories for human directors sitting at artillery in the field (fig. 11). Calculation occurred in series distributed across these media. Towards the war's end, engineers developed mechanical computers for the SCR-584 that directed the guns automatically. While the SCR-584 was designed for battlefield deployment in trailers, similar setups could be found in the bellies of planes, in hangars, and at airports. To each of these installations corresponded a constellation of images, screens, and operators specific to the local territorial conditions.

The images circulating within the network of a specific radar set coincided with a wider family of images that worked in tandem to stabilize the battlefield and produce a manageable territory. Nearly each step in this network of images effected a kind of screen test, by which some visual representation provided a regulative mechanism conditioning its users or controlling the flow of information. Flight training films inculcated in gunners and pilots the necessary discipline to perform in the heat of battle, providing a corollary in celluloid to the real-time navigation and targeting information supplied by ground and aerial radar systems; ${ }^{26}$ cameras mounted on guns and in cockpits recorded the performance of crew members, allowing for post facto reconstruction of team members' performance in battle; ${ }^{27}$ video maps inserted between the end of the cathode ray and the human operator facilitated the screening of the raw radar display with additional screens and images $;^{28}$ and aerial reconnaissance photography provided officers in 
command centers as well as navigators with means for touring enemy territory in advance of actual offensive missions. ${ }^{29}$ The essence of the radar screen, then, resided not so much within representations constrained by the circular frame of the oscilloscope but rather within a wider family of interactive images that managed the integration of human and machine elements around the task of producing and controlling territory.

\section{Psychophysics of the Scope Dope}

Electronic screens, radio waves, and jet propulsion redistributed visuality on the battlefield; psychology and physiology, aided by motion pictures, multiple choice tests, time-motion studies, photography, and Pavlovian bells, constructed visuality in laboratories. ${ }^{30}$ By the early 1940 s the United States and British militaries employed a growing staff of human scientists charged with training humans to receive, renew, and filter electronic signals. Research teams comprising psychologists, physiologists, sociologists, and medical doctors refashioned human perception for improved processing of data relayed by lenses, scopes, tubes, maps, protractors, cameras, timers, and other pieces of hardware. As testament to the growing cross-fertilization in mechanical factors and human factors, the director of US fire-control research during World War II, himself a Sperry veteran, declared that during the war he had "learned more from the psychologists than from the engineers." 31 The product of this psychophysical endeavor was the "scope dope," the colloquial term for radar operators, who eschewed individual perception in favor of a psychic apparatus of electromechanical relays. Their alleged dopiness testified to their successful externalization of sense in electronics.

Wartime research into how stress, duress, gender, temporal duration, visual ambiguities, acoustic stimulation, and amphetamine usage shaped the performance of radar operators set in motion a new knowledge of electronic screens and the human body. The study of how human bodies responded to hours gazing at screens was an urgent technological and physiological problem whose findings would shape the design of electronic screens and the training protocols of future information technology (IT) industries. The overlapping and nested research bodies enacting cognitive redistribution during the war included, for the United States, the Committee on Aviation Medicine, the National Defense Research Council, the Office of Scientific Research and Development, the Psycho-

logical Test Film Unit, the Applied Psychology Panel, and the Aviation Psychology Panel and, for the United Kingdom, the Medical Research Council Applied Psychology Research Unit. Researchers for these bodies 

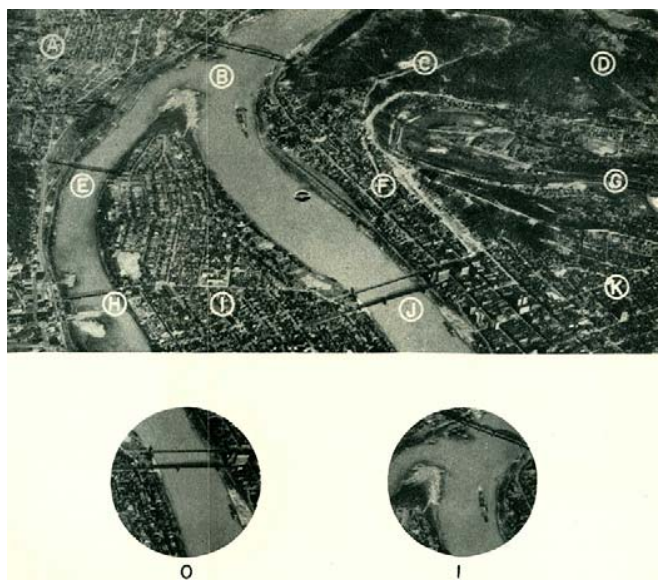

FIGURE 12. By the time radar operators reached the field they had been tested and trained on a wide battery of image technologies. For example, the "Spatial Orientation Test," an offshoot of aerial reconnaissance photography, tested radar operators' ability to correlate regions in large aerial photographs with detailed close-ups. In testing, operators had five minutes to assign a location to 48 detail images in total. This is one example of how military techniques deployed images for information processing and screening purposes. Source: Stuart W. Cook, Psychological Research on Radar Observer Training (Washington, DC, 1947), 291. Yale University Libraries.

typically identified a problem in human information processing that could be corrected with media technics. For example, US military researchers developed a measure of fourteen interrelated psychophysical aptitudes suitable for cultivation and managed enhancement through batteries of tests and exercises: skills at length and distance perception, mechanical experience, memory for landmarks, memory for visual patterns, numerical facility, speed of visual pattern discrimination, psychomotor coordination, psychomotor precision, spatial reasoning, insight into spatial relations, insight into rotational space, verbal comprehension, and visualization skills. ${ }^{32}$ Among the written tests, the Spatial Orientation Test (fig. 12) examined the ability to locate pre-identified landmark features in aerial photos of cities quickly, while the Spot Location Test gauged the ability to stably transpose coordinates across representations. Together, these and other studies provided a profile of how humans processed information in fast-moving environments characterized by data incoming along numerical, graphical, visual, tactile, and aural inputs.

In the decade after World War II, psychophysical mobilization put a growing emphasis on the coordination of complex teams around systems 


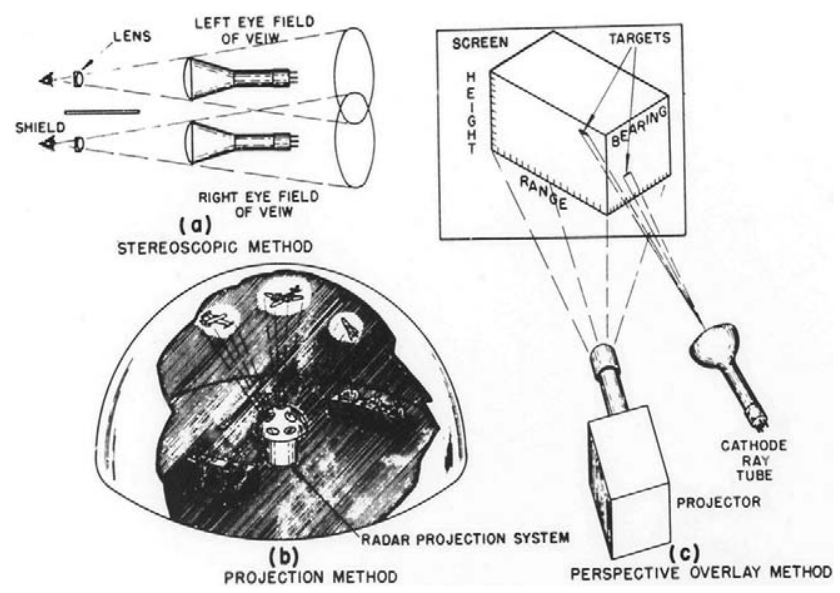

FIGURE 13. One example of the experimental radar screen technologies developed after World War II. This model sought to reproduce depth perception through projections on a curved dome. Source: J. W. Gebhard and E. A. Bilodeau, Appraisal of an Experimental Plan Position Indicator Representing Bearing, Range, and Height Information (Baltimore, 1947), 3. US Department of Defense, Defense Technical Information Center Archives.

with the aid of screens. One focus of this work was the development of improved screen technologies to facilitate better information processing and team collaboration. Centers such as the Systems Research Laboratory (1945-59), initially of Harvard University, brought together psychologists, physicists, time-and-motion engineers, engineers of radar and sonar systems, communication engineers, operations-research experts, and gunnery trainers to research improved setups for the communication of data across humans and their electronic counterparts. These studies aligned knowledge of data transmission rates and radio wave encoding with the optimal disposition of chairs, screens, plotting boards, and other human factors. ${ }^{33}$ Within these investigations, new screen technologies smoothed the most problematic links in the human-machine synthesis. Consider a 1947 Johns Hopkins University study of experimental PPIs carried out in concert with the Systems Research Laboratory. ${ }^{34}$ The study, which allied engineers with human scientists from the psychological laboratory, sought to resolve the unwieldy proliferation of screens and interfaces in World War II-era radar. It reviewed efforts to present range, elevation, and azimuth in a compact, threedimensional display (fig. 13). Although this effort involved the engineering of new interfaces, authors stressed that their inquiry was "psychological" in nature, aimed at determining "how accurately a man can understand and 
extract information from a display of this sort." 35 The resulting knowledge described human and machine as a composite engaged in a collaborative act of information screening.

These and other studies showcased how multimedia design could efficiently allocate information processing across humans and nonhumans. Designers of Combat Information Centers (CICs) and flight control centers gave to machines the role of tracking prescheduled flights and to humans the role of interpreting irregularities. ${ }^{36}$ Specialized screens and audio outputs promised to alert human operators to aberrations in prescheduled flights, thereby shifting the burden of screening the skies to exceptional events rendered in vivid multimedia. These allocations demanded the design of standard protocols for human users' multimedia outputs as well. For example, at a meeting on aviation communication held at the Pentagon, participants advocated for the standardization of speech protocols, the training of operators in more disciplined verbal articulation, and the enhancement of "circuit discipline" to control for noise as vital steps toward improving nationwide air traffic control. ${ }^{37}$ Studies in other military projects examined a broad range of design factors that shaped the performance of human-machine systems, including headset and microphone design, the relative advantages of differently colored over differently shaped console buttons, advantages of horizontal over vertically mounted screens, note taking, and even the effects of temperature on human judgment. ${ }^{38}$ Design of total communication systems produced an ever-finer attention to the integration of haptic, aural, and visual factors in electronics.

These studies of information processing in aerial defense systems came to enjoy a status in twentieth-century theories of mind comparable to that of the camera obscura in seventeenth- and eighteenth-century thought. ${ }^{39} \mathrm{~A}$ large part of this privileged epistemic status came from the stellar community of human scientists directly or indirectly enlisted in these studies between the 1940s and 1960s, including George A. Miller, J. J. Gibson, John L. Kennedy, Allen Newell, and J. C. R. Licklider. ${ }^{40}$ When one includes the entire complex of cybernetic researchers who based new theories of cognition on World War II fire-control research, the list rapidly expands to include Norbert Wiener, Claude Shannon, Margaret Mead, Gregory Bateson, Claude Lévi-Strauss, Roman Jakobson, and Harold Garfinkel. ${ }^{41}$ These scholars and their students launched a new understanding of cognition as distributed in external communications systems modeled on wartime studies of soldiers in complex aerial defense scenarios. Through the growing body of postwar research based on that model of human action, the scope dope became not merely one type studied by social science but rather its ideal type. As a paradigm of thought, this research discarded the heroic individual of classical liberalism and replaced it with an account of nodes 
in a complex network distributed across body, society, instruments, and the environment. Research in this tradition implied that every society possessed its own peculiar rationality in which particular bodies served merely as algorithmic filters for the communication of a collective computational unconscious.

David Riesman's celebrated 1950 invocation of radar in The Lonely Crowd to describe an emerging American personality type exemplified this generalization of the scope dope into a model American type. ${ }^{42}$ Earlier generations of Americans, according to Riesman, had been endowed with a sort of "psychological gyroscope" that, like the real gyroscope of naval navigation, had no need of external information processing equipment to provide a reliable orientation. ${ }^{43}$ In postwar America, those inner-directed types were being succeeded by a new sociality of other-directed types, who "must be able to receive signals from far and near; the sources are many, the changes rapid." The "one prime psychological lever of the otherdirected person is a diffuse anxiety. This control equipment, instead of being like a gyroscope, is like a radar." 44 Perpetually scanning the horizon, sending out signals and receiving messages, and getting its bearings by reference to a peer group on the one hand and an electronically mediated "screen of words," on the other, Riesman's radar-type projected onto an emerging postwar American population a subjectivity honed by the radar screens of World War II. ${ }^{45}$ In the coming decades the popularization of interactive digital screens modeled on radar displays secured that type's reproduction on a mass scale.

\section{Extension + Attention $=$ Multimedia}

As the compressed and focused attention of 1940s World War II hotspots dissolved into the indefinitely expanded temporal and spatial frontiers of 1950s cold warfare, extension and attention emerged as the principal challenges to effective aerial defense. Extension took the form of a vast American territory under threat by an enemy who could attack with devastating force and speed. By 1954, the rapidly augmenting aerial powers and munitions of the Soviet Union Strategic Air Command (SUSAC) had destroyed that sense of security two wide oceans had gifted to the continental United States. The squadrons of jet bombers commanded by SUSAC were capable of carrying hydrogen bombs at 600 miles per hour. ${ }^{46}$ Besides the fact that Soviet bombs' blast area outstripped the range of artillery batteries responsible for defending against incursions, even the best defense would fail to stop dozens or hundreds of enemies from delivering atomic payloads to targets across the United States. One mathematical simulation 
by Project RAND predicted the likely destruction of 30 to 60 percent of US war industries in the case of an all-out Soviet attack by air. ${ }^{47}$

The defensive problem of extension - the sufficient distribution of bodies in time and space-coincided with the need to maintain perpetual vigilance amidst mind-numbing monotony. America's Continental Air Defense Command (CADC), founded by the Joint Chiefs of Staff in 1954, was responsible for maintaining a defensive perimeter along 10,000 continuous miles of border enclosing 3,000,000 square miles of territory, twenty-four hours a day, seven days a week, three hundred and sixty-five days a year. Compounding this challenge was the rapid growth in civilian air traffic to some 25,000 annual flights in domestic air space whose constant comings and goings had to be monitored and checked against the unlikely but everpresent possibility of discreet or all-out enemy attacks. These indefinite threats demanded new forms of constant and definite attention. Widely dispersed radar defense networks needed to be porous but available for total, unhesitating mobilizations issued from centralized command locations. As a writer for Time commented, "Life on America's radar line-the 100-odd Aircraft Control and Warning stations-is an unsettling mixture of utter monotony and utmost intensity. Although every operator knows that the next blip on his radarscope could be the herald of death, staring steadily into the electronic eye can be endlessly boring." 48

The interactive computer screens of SAGE provided an integrated solution to these problems of extension and attention. As early as 1950, engineers at Massachusetts Institute of Technology (MIT) identified interactive displays with a graphical interface as the key to establishing continuous human-computer communications. Their implementation at first appeared cost-prohibitive. ${ }^{49}$ That changed when, in 1951, the Air Force awarded MIT a contract to develop a computerized air defense system (only later dubbed SAGE) that could assign computers the task of tracking planes and targeting trajectories while giving to human users-bound together by media such as telephones, screens, and maps-the tasks of confirming identifications, deciding responses, and calculating trajectories for interception. ${ }^{50}$ The need for screens was related to the innovative conception of computerized defense as a particular kind of dynamic and holistic system. Early proposals labeled the air defense project an "organism," that is, "a structure composed of distinct parts so constituted that the functioning of the parts and their relations to one another is $[s i c]$ governed by their relation to the whole." ${ }^{51}$ The command and control structure distributed across human and nonhuman networks demanded an interactive display system that could rapidly relay information across these myriad steps. The most routine aspects of attention and extension-monitoring far-flung regions, isolating aberrant flight paths-would be assumed by the digital computer. The 


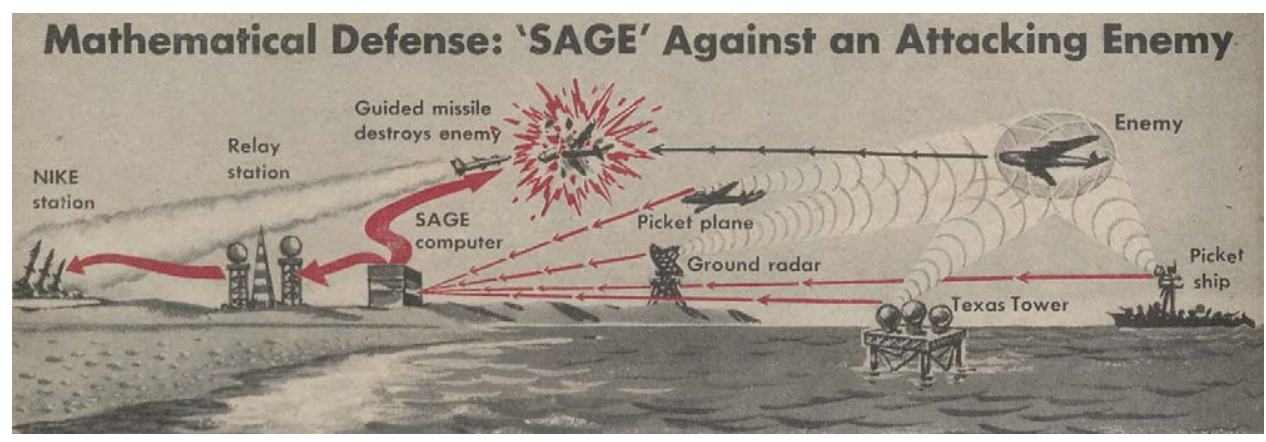

FIGURE 14. Depiction of the main components in a coastal SAGE sector during an engagement with the enemy. Source: "The Master Mind," Newsweek 47, no. 5 (January 30, 1956): 88.

concentration of human judgment on decision-making in case of the unexpected events called for displays that would offer an up-to-date portrait of the situation in the field and its precisely calibrated evaluation by the machines.

Within the computerized aerial defense organism, interactive multimedial consoles-including screens, light guns (forerunners of the mouse), sound notifications, telephones, a variety of push-button haptic interfaces, and even ashtrays-expanded the channels of engagement between digital system and the user's sensory apparatus. Through these channels, what Simondon termed the "margin of indetermination" in informationprocessing machines invited human participation. "As soon as we received that contract," an engineer in the aerial defense project recalled, "we needed more computers and more displays." Larger, more sophisticated information processing meant more numerous visual displays and consoles for its manipulation. Based on a demo defensive system first mounted in Cape Cod, and given the limited task of monitoring and controlling air space around New England, MIT designers "realized that we needed a manmachine interactive display system to exercise control and soon found we needed a lot of displays to control over 400 aircraft simultaneously. My estimate of 32 consoles grew to 64 and then to $82 .{ }^{52}$ By 1953, the model Cape Cod System was up and running with a centralized "direction center" filled with the first computer-generated PPI screens and equipped with a keyboard for inputting feedback. ${ }^{53}$

The Cape Cod System and its consoles became the model for the national SAGE air defense system, first announced in 1956 and put into partial operation in June $1958 .{ }^{54}$ Designers envisioned a network of local direction centers and regional command centers distributed across North 


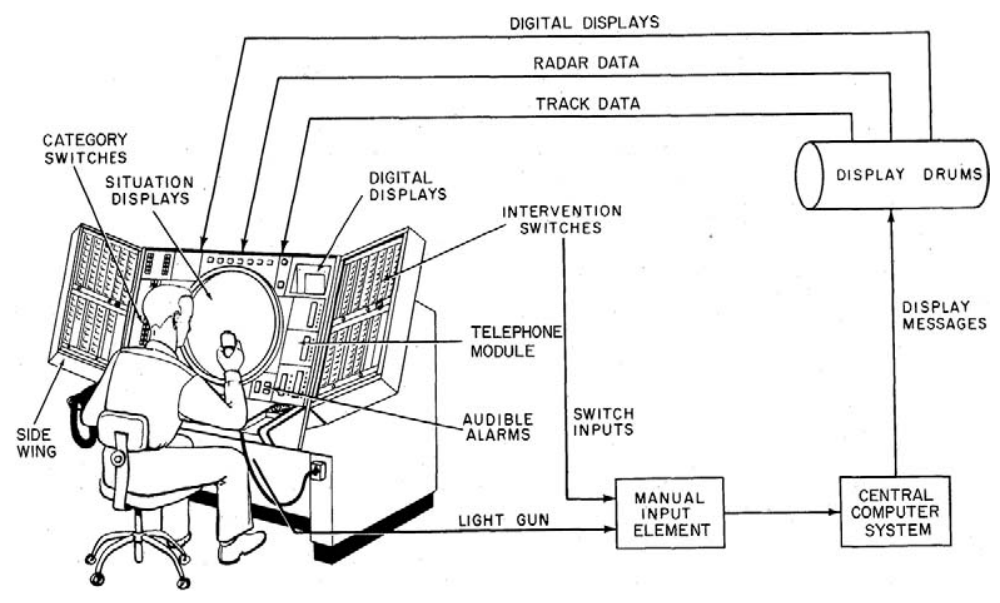

FIGURE 15. Diagram of a SAGE console depicting large central situation display screen, a smaller digital display, two wings, the major interface elements (screens, buttons, light gun, telephone, alarm), the major channels of information flow, and the human operator. Source: Theory of Operation of Display System for AN/FSQ-7 Combat Direction Center and AN/FSQ-8 Combat Control Central, Volume I, 18.

America, each of which used massive digital computers and networked communication to rapidly collect, process, and present data on aerial defense scenarios across the United States (fig. 14). Data gathered from airborne radar, picket ships, Texas towers (so-named for their resemblance to drilling platforms in the gulf off of Texas), and heavy radar installations on land, along with information fed in by ground observers, weather stations, and prerecorded flight plans, streamed through the AN/FSQ-7 direction center computer and AN/FSQ-8 combat center computer, which generated real-time images for the display of hundreds of interactive computer screens located in each center. The mutability of digital information allowed rapid communication across vast distances as well as real-time, multimodal interactions.

SAGE launched a new regime of territorial production through an assemblage of computers and human operators networked together by computer screens. Foremost in this production was the standard doublescreened situation display (SD) console featuring an array of buttons, an interactive light gun, and an audio speaker (the term "situation display" referred to both the large CRT displaying the aerial "situation" and the entire console that hosted that CRT; fig. 15). Its main screen was a nineteen-inch circular PPI joining textual characters with figurations of flight vectors and cartography. Every 2.62 seconds the screen refreshed to deliver a moment-by-moment "graphic display of the changing air situation, with 
correct geographical relations between fixed points and moving targets." 55 (fig. 4). An additional five-inch square CRT displayed letters, numerals, and special symbols concerning matters too static, wordy, or space consuming to appear on the main screen. ${ }^{56}$ An array of switches on "wings" flanking the left and right sides of the central console enabled the interactive operations, such as switching the display between different "layers" of information or zooming in on particular quadrants. The interactive light gun allowed operators to label vectors onscreen as friend or foe. Regularly scheduled flights were programmed into the direction center's computer in advance, allowing for the computer to assume the task of correlating routine flights with their prescheduled flight plans. Rather than constantly correlate the flights observed with written records, now the human operators could focus their attention on decision making in situations of uncertainty. Interaction with the system, rather than record keeping, became the operators' central task.

The grouping of screens into clusters of tasks, on the one hand, and the layers of screening operations, on the other, reflected the designers' intent that each console "display only those classes or parts of messages determined by the tactical problem assigned to the operator," thereby making each screen function in a complex of human-nonhuman operations distributed throughout the direction center. ${ }^{57}$ The center itself comprised the air surveillance room, which was charged with monitoring all flight tracks (fig. 3) and distinguishing ally from enemy; a weapons direction room for evaluating the threat of hostile tracks and targeting weapons appropriately; a command post or "control room" where officers surveyed information on the large screen and correlated it with communications from officers in adjacent sectors (figs. 16-17); and a simulation room for training purposes. ${ }^{58}$ As of the late $1950 \mathrm{~s}$, a national control room at the CADC in Colorado consolidated data from the sectors into a unified national picture. On account of the difficulty in instructing a computer how to filter noise like weather disturbances from its rendering of the aerial situation, engineers designed a mapping display whose surface could be marked up with crayon to screen the uptake of data into the computer by cameras mounted overhead (fig. 18).

Assembled, SAGE screens produced a unified screenscape. The modularity of electronic data, the serialization of time, and the granular disassembly of physical space into large swaths composed around time-critical operations enabled the production of this screenscape. Accounts of SAGE in LIFE, Time, Newsweek, and similar weeklies sought to produce a picture of this territory composed of bodies, techniques, instruments, and signs, but the result was flashy publicity and earnest prose. In Your Defense, an educational film from the period produced by the United States Air Force, 


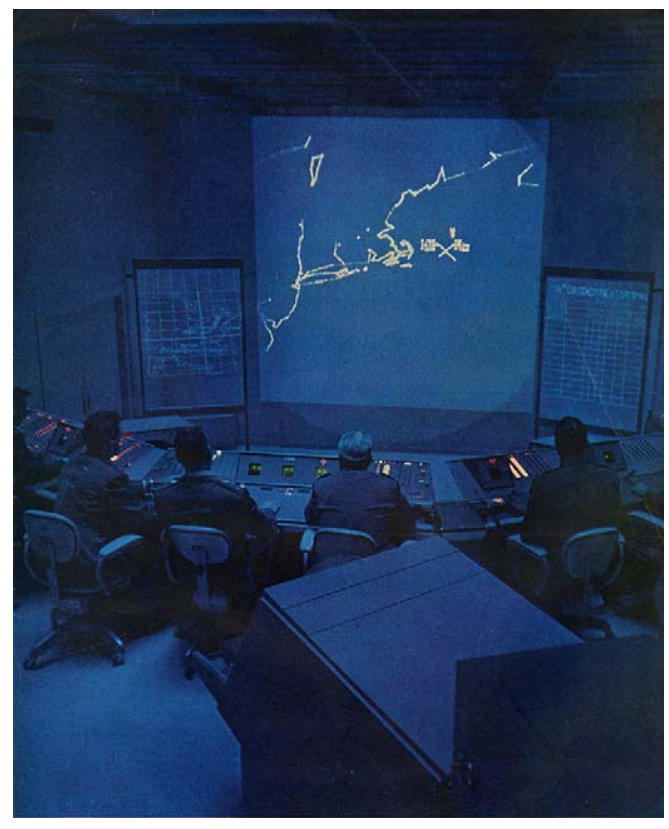

FIGURE 16. Photograph of a SAGE command post featuring installations for the commanding officers, a projection screen at the front of the room displaying the overall aerial situation, and a situation display at the back of the room (foreground) for a more detailed, interactive view of the aerial situation. Source: "Pushbutton Defense for Air War," LIFE 42, no. 6 (1957): 62.

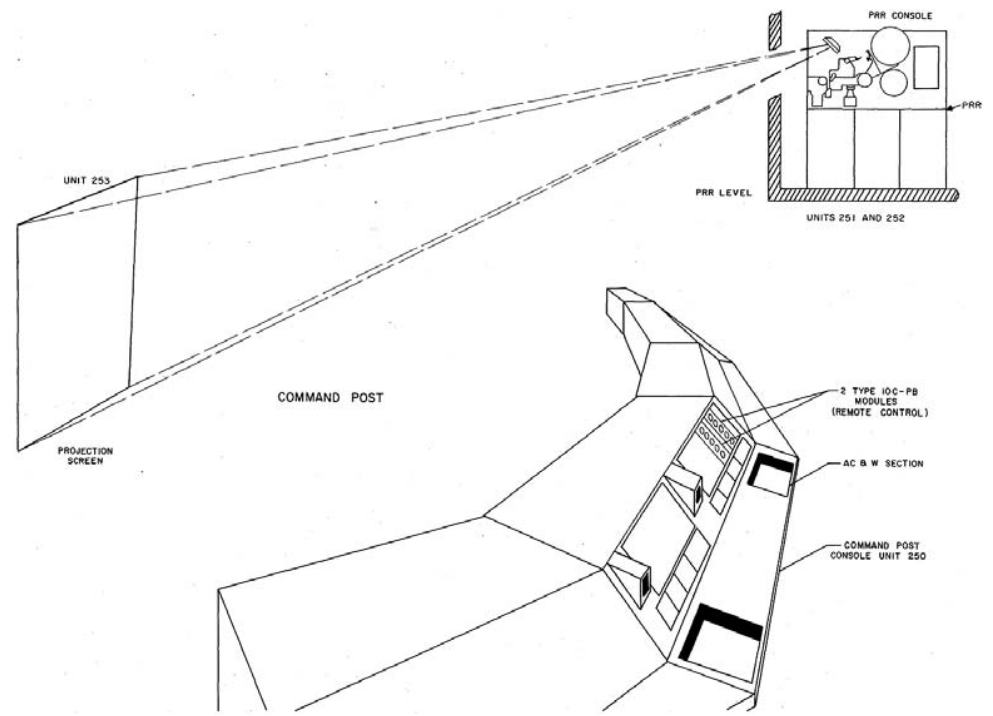

FIGURE 17. Schematic diagram of the command post and its projection apparatus. Approximately twice a minute an analog slide of the electronic scene on the situation displays would be developed and projected. Five officer outposts arrayed around the screen are also depicted. Source: Theory of Operation of Display System for AN/FSQ-7 Combat Direction Center and AN/FSQ-8 Combat Control Central, Volume II (Kingston, NY, 1958), 2. 


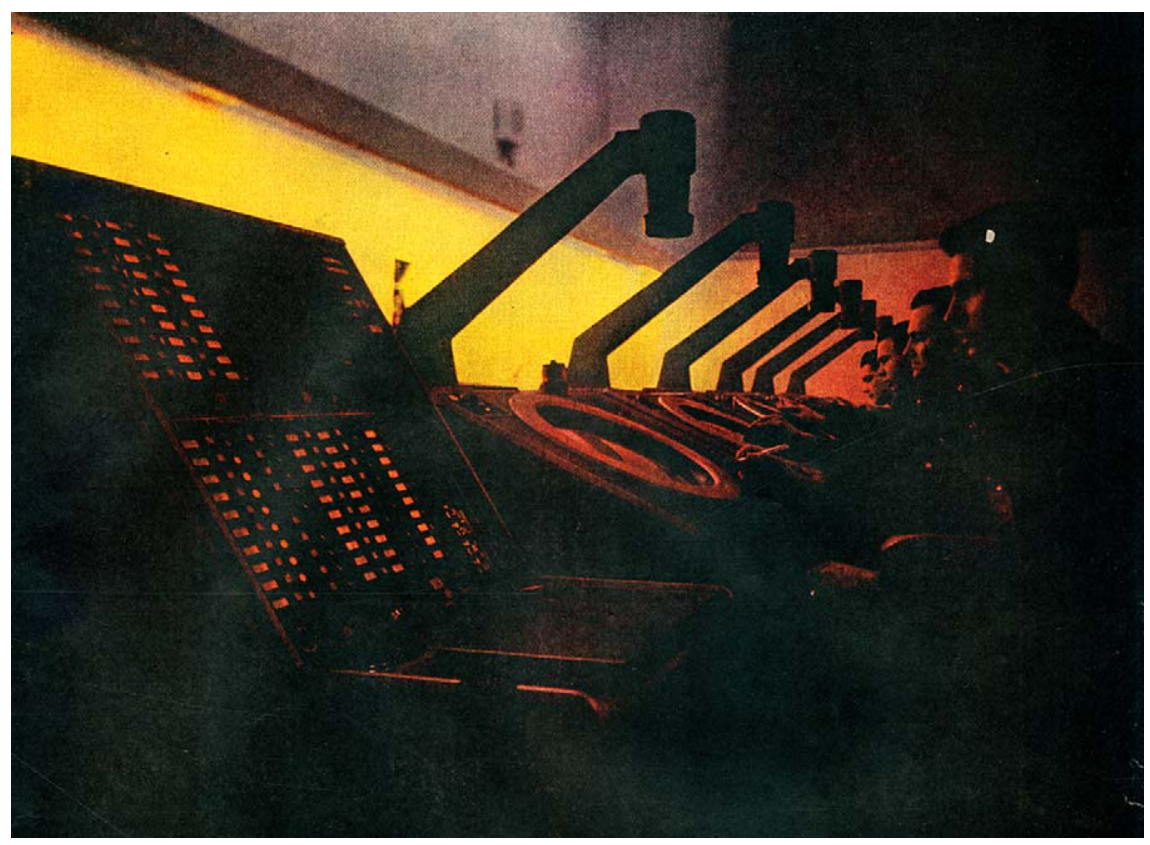

FIGURE 18. The SAGE direction center video mapping consoles. The photoelectric devices overhead picked up graphics for processing into digital data for presentation on the situation displays and the command post projection. The layering of analog, digital, human, machine, and material (i.e., crayon marking) elements characterized the entirety of the SAGE network and its strategic distribution of screening operations. Source: "Pushbutton Defense for Air War," LIFE 42, no. 6 (1957): 65.

economically encapsulated the ecology of operations relayed across the screens of SAGE. ${ }^{59}$ In a dramatized air raid, streams of data-collected from long-range radar posts, airborne radars in the bellies of planes overhead, radar picket ships, gap filler radars in the gaps between other outposts, Texas towers, and centers collating data on flights and weather-flash up on the situation displays, with audible alarms in the case of aberrancies and emergencies. Screening operations leap from the air surveillance room, where operators scan the sky for unfamiliar flights, to an identification room where operators sort friend from foe, and then to the command center where an officer issues orders to the weapons director who launches jets charged with clearing the sky of foreign elements. Information collated from multiple directions is forwarded to the centralized command center at North American Aerospace Defense Command (NORAD), a central control base in the Cheyenne Mountains of Colorado with real-time access to 
radar from across the continent. ${ }^{60}$ At each location a family of consoles, screens, and projections receives data from multiple sources, isolates key elements, presents data for human action, and collates that information for relay up the chain.

\section{The Subject of the Interactive Digital Image}

The present-day digital image and its screens can be traced to this family of images involved in computational screening for aerial defense. That circular screen that presented the first nontrivial, instrumentally effective working computer screen, embedded on a console and operated by a human user, originated in a chain of screening operations that distributed information processing along complex networks of humans and nonhumans. This chain of screening operations furnished up-to-date pictures of the frontiers of an American territory SAGE itself produced. These multimedia operations produced new regimes of sovereignty for a president empowered, through NORAD and its webbed network of subordinates, to command and control a national territory whose contours coincided with the electronic screens reconstructing it. This computer screen also produced new regimes of human dependence for those reliant on digital machines to process and display information about the integrity of national territory. The interactive computer screen became the central mechanism for holding together this territory and the push-button a symbol of the era of warfare it sustained. ${ }^{61}$

Recognizing SAGE interfaces as integral to the history of computing changes our account of what kind of psychic apparatus networked computing is. SAGE not only fashioned screens, alarms, buttons, and light guns but also shaped gazes, reflexes, and sociality among its teams of operators. The aforementioned features of the electronic image-its constant updating, its ability to change segment by onscreen segment, the mutability of its representations-reflected the inadequacy of traditional maps and other media to the spatiotemporal rations of modern aerial defense. Just as a new kind of psychic and strategic disposition belonged to the rise of this computer system, so too it introduced an entirely new technical apparatus. In order to implement SAGE, military engineers developed many of the hallmarks of modern digital computing, including effective algebraic languages, magnetic core memory, synchronous parallel logic, touch-screen technology, networked computing, video displays, and computer graphics. The need for a new set of highly responsive and distributed technologies, like the need for the integration of humans into computer problem-solving series, ushered forth the 
apparatus of modern computing. ${ }^{62}$ The digitally generated image, the temporality of its networks, its storage mechanisms, its processing languages, and the psychology of its users matched the US strategic circumstances of the early Cold War, forming common elements of a single problem.

The psychological hallmarks of the scope dope also point toward the design parallels that prevailed between Cold War arts and military engineering. As communications historian Fred Turner has argued, midcentury multimedia designers based in the United States, such as Bauhaus refugee Herbert Bayer and designers Charles and Ray Eames, crafted a new genre of multimedia exhibitions with an eye to cultivating dynamic liberal subjects capable of navigating the complex flows of information and difference characteristic of a modern liberal democracy. ${ }^{63}$ The challenges they faced and the solutions they reached echo those of SAGE engineers. In military strategy as in popular culture, the rise of the United States as a superpower opened up new challenges for coping with the flow of persons, things, and ideas. In military strategy, as in arts and ideas, multimedia offered a strategy for buffering the overwhelming global flows buffeting national systems. Scope dopes adapted to multiple flows, negotiated competing inputs, and critically screened incoming information to produce a secure yet porous national space.

\section{The Martial Aesthetic of the Attention Economy}

The screening technologies of midcentury air defense gave rise to the conception of computing as a multimedia collaboration among humans and machines. This idea emerged most concretely in the work of three seminal theorists of human-computer interaction: J. C. R. Licklider, Ivan Sutherland, and Douglas Engelbart, whose work on the computer systems of midcentury air defense provided the basis for multimedia interactive computing. Licklider, a psychologist who worked on human factors in SAGE, announced the new era of human-machine collaboration with his seminal 1960 paper "Man-Computer Symbiosis." Abandoning notions of computer and user as slave and master, Licklider likened them to interdependent organisms akin to a plant and its pollinating insects. ${ }^{64}$ His colleague Sutherland, considered the father of graphical user interfaces, adapted SAGE hardware for the 1962 Sketchpad software, which introduced graphics and a light pen as a primary instrument for real-time collaboration between human and computer ${ }^{65}$ Engelbart credited his experience as a radar operator with inspiring the host of interactive and graphical technologies adopted in personal computing of 
the 1970s and 1980s. For Engelbart, "radar offered a model of a "virtual datascape" capable of rendering any information in lively animated graphical and haptic forms. ${ }^{66}$ The field of computer gaming similarly evolved through modest adaptations of radar defense. Early games, such as Pong (1972) and Space Invaders (1978), were little more than digital exercises in aerial interception adapted for recreational use. ${ }^{67}$ Users merely assumed the role formerly played by the SAGE operator, with aliens and tennis balls taking the place of Soviet projectiles. By the 1980s personal computing and arcade games were delivering the multimedia interfaces developed around SAGE into homes and neighborhood malls across the United States.

Parallel with the development of these new theories and products, SAGE gave rise to a global software industry premised on the mediations of vigilant humans in time-critical operations. Accounts of the digital computer prior to SAGE, such as John von Neumann's seminal 1945 report on the Electronic Discrete Variable Automatic Computer (EDVAC), had defined the computer in terms of a self-contained system. With SAGE, a new conception of computing as based on a mixture of practices, techniques, instruments, and persons - that is, "software"-took shape. ${ }^{68}$ The company charged with developing SAGE software, the Systems Development Corporation (SDC), quickly grew to become the largest software company in the world, with its projects and personnel planting seeds for the logic of the 1970s and 1980s software industry. ${ }^{69}$ The tremendous success of SDC came about by taking the situation of aerial defense teams, bound together by computerized radar defense, as the paradigm for software projects generally. It brought this ethos to work for domestic clients that included the Los Angeles Police Department, National Aeronautics and Space Administration (NASA), Department of Transportation (DOT), and Environmental Protection Agency (EPA) and international projects that included command and control systems in Africa, Europe, and Asia; an automated weather reporting system in India; an earthquake warning system in Australia; and military training projects operated globally. ${ }^{70}$ These projects imparted a temporality of crisis to modern information processing and to the burgeoning software industry, according to which the computer was an open system sustained by users perpetually engaged in time-critical operations for collective success.

The principal icon of this new sociotechnical paradigm was the interactive digital screen, whose technical hallmarks (processual, interactive, modular, gridded, time-critical) corresponded to a logic of continuous screening, regulating, enlisting, breaking-down of space, mapping, and time-sensitive operations. That screen permitted a redistribution of human perceptions in ratios strategically matched to the challenge of jet 


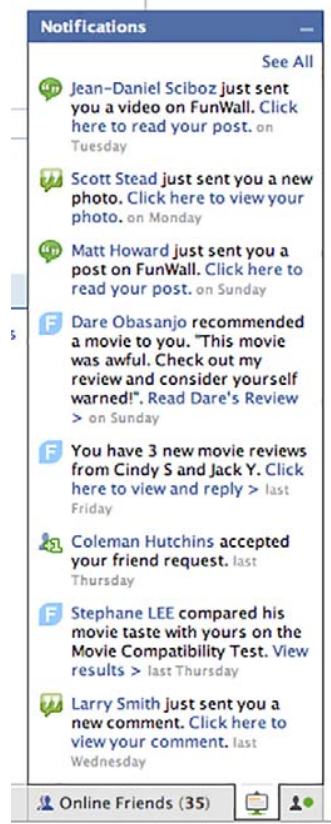

FIGURE 19. Facebook notification panel mixing characters, icons, alerts, affordances for voice communications, and a network of real-time peers within an electronic interface. "Facebook Notifications" by Stowe Boyd is licensed by Creative Commons Attribution-Non-Commercial 2.0.

propulsion and modern munitions. Users of that screen attuned their operations to the coordinates produced by an array of humans and instruments; they perpetually waited on incoming signals, ready to respond to them at a moment's notice with a sophisticated network of mechanical aids to compose and relay a response. To these tasks corresponded a generalized experience of anxiety as well as a particular distribution of time and space around long pauses punctuated by intense moments of concentrated action. As modeled by military studies of vigilance, stress, and teamwork, these subjects were dynamic, adaptive types, capable of mobilizing their resources in response to sudden stress, cohering into integrated collaborative systems to meet the urgent threats of external agents. They traded experience for information, heroic individualism for well-ordered information ecologies.

From the 1990s onward, the World Wide Web incorporated this martial aesthetic honed in aerial defense into a burgeoning attention economy. The time-critical temporality of aerial defense became paradigmatic for an infinitely expandable base of users and devices whose ability to collect and process data depended on successfully recruiting user vigilance. Students and employees alike incorporated just-in-time production and readiness for time-critical signals from afar into the everyday activities of work and leisure. Features of interactive screens of midcentury aerial defense-tones 
signaling the arrival of a message, urgent notifications interrupting the frame of the screen, headsets permitting real-time networked communications, and the mingling of flying graphical and textual elements-emerged as part of the standard stock of techniques for leveraging users into a state of constant alert (fig. 19). Echoing the co-emergence of national television and computer-generated images in the 1950s, where a new electronic screen permitted a new experience of immediacy to vast terrains, late twentiethcentury television also mutated to parallel the temporality and mentality of computational screening. The threat of crisis and catastrophe, the sudden and destructive eruption of the unexpected that animated the liveness of television for decades, has become in the late twentieth- and early twentyfirst centuries the phenomenon of cable news-and thus mutated into a kind of twenty-four-hour catastrophe machine, perpetually scanning the globe for intrusions in the flux of everyday monotony. ${ }^{71}$ In this way, computational screening aligned itself with an attention economy familiar to those of us constantly mobilized by our digital devices to practice vigilance in monotony, to beware the eruption of the unpredicted amidst the incessant transmission of indifferent information.

\section{Notes}

I thank Jean Day and members of the Representations editorial board for their invaluable feedback on this manuscript. The research for this article was funded in part by the Mellon Foundation and its Genealogy of the Excessive Screen Sawyer Seminar. Much of the research for the article was completed while I was a visiting professor in the Film and Media Studies program in 2016 and 2017 at Yale University and a fellow at Yale's Whitney Humanities Center in autumn 2017. The article forms part of a larger book project on screenscapes and ecologies of operations that I am co-authoring with Francesco Casetti, whom I thank for his careful reading and comments on this text. I thank audiences at Yale University (and particularly respondent Rudiger Campe and colleague Craig Buckley) and Harvard University (particularly my hosts Mingyi Yu and Laura Frahm) for their feedback, as well as Lisa Åkervall, Matthew Kirschenbaum, Paul Michael Kurtz, Dennis McNulty, David Mindell, Fred Turner, and, especially, Seth Watter. For aid finding and reproducing images, I thank Mal Ahern of Yale University, Krista Ferrante of the MITRE Corporation, and the staff of Yale University Libraries.

1. Charlie Gere, "Genealogy of the Computer Screen," Visual Communication 5, no. 2 (2006): 141-52.

2. For a general introduction to the early years of computer graphics, see recollections of their development at MIT in connection with computerized radar research in Jan Hurst et al., "Retrospectives: The Early Years in Computer Graphics at MIT, Lincoln Lab and Harvard," in SIGGRAPH '89 Panel Proceedings (New York, 1989), 19-73. On James Whitney's adaptation of analog computers used for fire-control to experimental animations, see Zabet Patterson, "From 
the Gun Controller to the Mandala: The Cybernetic Cinema of John and James Whitney," Grey Room 36 (Summer 2009): 36-57. On radar defense and the development of Tennis for Two, see Claus Pias, "The Game Player's Duty: The User as the Gestalt of the Ports," in Media Archaeology: Approaches, Applications, and Implications, ed. Erkki Huhtamo and Jussi Parikka (Berkeley, 2011), 164-83; and Claus Pias, Computer Spiel Welten (Berlin, 2002), 63-65. On the development of Ivan Sutherland's Sketchpad, see Ivan E. Sutherland, "Sketchpad: A ManMachine Graphical Communication System," in The New Media Reader, ed. Noah Wardruip-Fruin and Nick Montfort (Cambridge, MA, 2003), 111-26; and Jacob Gaboury, "Image Objects: An Archaeology of Computer Graphics, 19651979" (PhD diss., New York University, 2014), 196-99.

3. Kyle Stine, "The Coupling of Cinematics and Kinematics," Grey Room 56 (Summer 2014): 36, https://doi.org/10.1162/GREY_a_00149.

4. Gilbert Simondon, On the Mode of Existence of Technical Objects, trans. Cécile Malaspina and John Rogove (Minneapolis, 2017), 17.

5. On robots, automata, and science fiction, see ibid., 16-17, 20; and Jean Baudrillard, The System of Objects, trans. James Benedict (London, 1996), 128-32.

6. Pamela M. Lee, "Aesthetic Strategist: Albert Wohlstetter, the Cold War, and a Theory of Mid-Century Modernism," October 138 (Fall 2011): 27.

7. Friedrich A. Kittler, Optical Media: Berlin Lectures 1999, trans. Anthony Enns (Malden, 2010), 225, 226.

8. Wolfgang Hagen, "Es gibt kein 'digitales Bild'. Eine medienepistemologische Anmerkung," Archiv für Mediengeschichte 2 (2002): 103-12; Claus Pias, "Das digitale Bild gibt es nicht: Über das (nicht-)Wissen der Bilder und die informatische Illusion," Zeitenblicke 2, no. 1 (2003).

9. On iconoclasm, see W. J. T. Mitchell, Iconology: Image, Text, Ideology (Chicago, 1986), esp. 112-15. For a selection of writings in the tradition of digital iconoclasm, listed in approximate order of their initial public presentation (rather than English translation), see Vilém Flusser, Into the Universe of Technical Images, trans. Nancy Ann Roth (Minneapolis, 2011); Friedrich A. Kittler, "Computer Graphics: A Semi-Technical Introduction," trans. Sara Ogger, Grey Room 2 (Winter 2001): 30-45; Frieder Nake, "Das doppelte Bild," Bildwelten des Wissens 3, no. 2 (2005): 40-50; Alexander R. Galloway, The Interface Effect (Malden, 2012), 1724; and Jacob Gaboury, "Hidden Surface Problems: On the Digital Image as Material Object," Journal of Visual Culture 14, no. 1 (2015): 40. My discussion of digital iconoclasm is indebted to two critical sources in particular: Ricardo Cedeño Montaña and Christina Vagt, "Constructing the Invisible: Computer Graphics and the End of Optical Media," Communication +17, no. 1 (2018); and Kyle Stine, "Critical Hardware: The Circuit of Image and Data," Critical Inquiry 45 (Spring 2019): 762-86.

10. See, for example, Jonathan Crary, Techniques of the Observer: On Vision and Modernity in the Nineteenth Century (Cambridge, MA, 1990), 2.

11. Peter Galison, "The Ontology of the Enemy," Critical Inquiry 21, no. 1 (1994): 228-68.

12. The history of computers as control mechanisms presents computers as technologies of articulation and intervention whose operations intertwine with their environment. In control systems, the physical world and algorithms often exist on a continuous plane, and no crisp opposition exists between representation and represented, material and ideal, continuous and discrete, and so on. Select accounts that locate computing technologies in the development of control systems include Otto Mayr, The Origins of Feedback Control (Cambridge, MA, 
1970); David A. Mindell, Between Human and Machine: Feedback, Control, and Computing Before Cybernetics (Baltimore, 2002); and Seb Franklin, Control: Digitality as Cultural Logic (Cambridge, MA, 2015).

13. "The eyes," Kittler argues in one passage, "can only access these signals at the beginning and end of the transmission chain, in the studio and on the screen," i.e. outside the transmission system proper. See Kittler, Optical Media, 226. For one of his many invocations of Claude Shannon's model as paradigmatic of communications in general, see 43-46 in that same volume.

14. California Academy of Sciences, "Radar Defense Screen," Science in Action, March 30, 1954, online at https://archive.org/details/Sciencei1956_5. The 1956 date listed online appears to be incorrect, or at least does not refer to the initial date of broadcast. I have instead used the copyright date cited in the Library of Congress catalog of copyright entries.

15. On screening as a media theoretical problem, see Jeremy Packer and Kathleen F. Oswald, "From Windscreen to Widescreen: Screening Technologies and Mobile Communication," Communication Review 13, no. 4 (2010): 309-39; and W. J. T. Mitchell, "Screening Nature (and the Nature of the Screen)," New Review of Film and Television Studies 13, no. 3 (2015): 231-46. On radar and SAGE as screening technologies, see Jeremy Packer, "Screens in the Sky: SAGE, Surveillance, and the Automation of Perceptual, Mnemonic, and Epistemological Labor," Social Semiotics 23, no. 2 (2013): 173-95.

16. Valérie November et al., "Entering a Risky Territory: Space in the Age of Digital Navigation," Environment and Planning D: Society and Space 28, no. 4 (2010): 582 and 585 .

17. I borrow the term "time-critical" from Wolfgang Ernst, who defines it as "a special class of [media-based] events where exact timing and the temporal momentum is 'decisive' for the processes to take place and succeed at all." See Jussi Parikka, "Ernst on Time-Critical Media: A Mini-Interview," Machinology: Machines, Noise, and Some Media Archaeology by Jussi Parikka (blog), March 18, 2013, https://jussiparikka.net/2013/03/18/ernst-on-microtemporality-amini-interview/. See also Axel Volmar, ed., Zeitkritische Medien (Berlin, 2009). While I fully embrace Ernst's refusal to reduce time-critical operations to a temporality defined entirely in terms of human experience, in the case of SAGE it is equally impossible to expel human experience from this temporality.

18. On this testing of the thresholds of visibility and representation by radiation and atomic energies, see Akira Mizuta Lippit, Atomic Light (Shadow Optics) (Minneapolis, 2005).

19. The Science in Action episode thus belonged to a family of postwar technologies, such as duck-and-cover school training for bombing raids and lavishly illustrated magazines on Cold War mobilization, that cultivated constant readiness in view of the fraying distinctions between homeland and battlefront, peace and war. For more on this fraying of distinctions, see Beatriz Colomina, Domesticity at War (Cambridge, MA, 2007).

20. See, for example, Bernhard Siegert, "The Chorein of the Pirate: On the Origin of the Dutch Seascape," Grey Room 57 (Fall 2014): 6-23.

21. Mindell, Between Human and Machine, 22.

22. For more on the Battle Tracer, its operations, and the context of its development, see Thomas Parke Hughes, Elmer Sperry: Inventor and Engineer (Baltimore, 1971), 232-33; James R. Beniger, The Control Revolution: Technological and Economic Origins of the Information Society (Cambridge, MA, 1986), 304-7; Thomas 
Parke Hughes, American Genesis: A Century of Invention and Technological Enthusiasm, 1870-1970 (New York, 1989), 135-37; and Mindell, Between Human and Machine, 30-35. For a primary document on the Fire Control System and its operations, see the publisher's catalog The Sperry Fire Control System (New York, 1916). Courtesy of Hagley Museum and Library, Wilmington, Delaware.

23. Hughes, Elmer Sperry: Inventor and Engineer, 232-33; Mindell, Between Human and Machine, 31-32.

24. Robert Buderi, The Invention That Changed the World: How a Small Group of Radar Pioneers Won the Second World War and Launched a Technical Revolution (New York, 1996), 53.

25. Ibid., 52.

26. For more on the use of film in aviation testing and training during World War II, see the primary document James J. Gibson, Motion Picture Testing and Research, Aviation Psychology Program Research Reports (Washington, DC, 1947).

27. See, for example, Standards and Curriculum Division, "Aircraft Fire Control," Navy Training Courses (Washington, DC, 1944), 127.

28. John S. Hall, ed., Radar Aids to Navigation (New York, 1966), 268.

29. On aerial reconnaissance in World War I, see Bernhard Siegert, "Luftwaffe Fotografie. Luftkrieg als Bildverarbeitungssystem 1911-1921," Fotogeschichte: Beiträge zur Geschichte und Ästhetik der Fotographie 12, no. 45/46 (1992): 41-54; and Allan Sekula, "The Instrumental Image: Steichen at War," Artforum 14, no. 4 (December 1975): 26-35. For more on its use in training and testing in World War II, see the primary document Stuart W. Cook, "Psychological Research on Radar Observer Training," Aviation Psychology Program Research Reports (Washington, DC, 1947), 291, Yale University Libraries.

30. See, for example, the wartime reports and summaries of wartime research: Office of Scientific Research and Development, "Range Finders and Tracking," Summary Technical Report of Division 7, National Defense Research Committee (NDRC) (Washington, DC, 1947), 67-146; "Radar Operator 'Fatigue': The Effect of Length and Repetition of Operating Periods on Efficiency of Performance," Applied Psychology Panel, NDRC, Project SC-70, NS-146, Selection and Training of Oscilloscope Operators, January 4, 1944; J. K. Adams, D. C. Beier, and H. A. Imus, "The Influence of the Visual Tasks Required of Personnel in the 16 Weeks Fire Controlmen (O) Training Course Upon Their Visual Proficiency," Applied Psychology Panel, NDRC, Project N-114, Selection and Training of Rangefinder and Radar Operators, August 1, 1944; N. H. Mackworth, "The Breakdown of Vigilance during Prolonged Visual Search," Quarterly Journal of Experimental Psychology 1, no. 1 (1948): 6-21 (declassified publication of formerly classified wartime research). I thank Oliver Gaycken for sharing with me his unpublished research into the importance of moving images for training and testing soldiers, discussing the wartime work of J. J. Gibson in particular: Oliver Gaycken, "Cinema Is 'I Fly': J. J. Gibson and the Work of the Army Air Force's Psychological Test Film Unit," unpublished. On the mobilization of vigilance, in particular, see the excellent secondary source Kenneth Rogers, The Attention Complex: Media, Archeology, Method (New York, 2014), 78-89.

31. Joseph C. Boyce, ed., New Weapons for Air Warfare: Fire-Control Equipment, Proximity Fuzes, and Guided Missiles (Boston, 1947), 75.

32. Cook, "Psychological Research on Radar Observer Training," 24-26.

33. Throughout this paragraph I draw on Henry McIlvaine Parsons, Man-Machine System Experiments (Baltimore, 1972), 107-13. 
34. J. W. Gebhard and E. A. Bilodeau, Appraisal of an Experimental Plan Position Indicator Representing Bearing, Range, and Height Information (Baltimore, 1947), 3. US Department of Defense, Defense Technical Information Center Archives, http://www.dtic.mil/dtic/tr/fulltext/u2/639287.pdf.

35. Ibid., v.

36. See, for example, the primary source Joseph G. Adiletta and Robert L. Chapman, "Layout of the Combat Information Center in the PO-2W Aircraft," Technical Report, SDC Human Engineering Project 20-F-4, Project NR-784-006 (New York University, April 1951), Defense Technical Information Center Archives; and the secondary source Layne Karafantis, "NORAD's Combat Operations Center: A Distinctively Cold War Environment," Information E Culture: A Journal of History 52, no. 2 (2017): 139-62.

37. Office of Naval Research, "Minutes of the Conference on Aviation Communication Systems" (The Pentagon, Washington, DC: Department of the Navy, June 7, 1951), esp. 3-6, Yale University Libraries.

38. Examples drawn from Joan C. Robinette, "Bibliography on Aeromedical Research with Abstracts" (Aerospace Medical Laboratory, December 1959), 1-3, Defense Technical Information Center Archives, http://www.dtic.mil/ $\mathrm{dtic} / \mathrm{tr} /$ fulltext/u2/a955081.pdf.

39. Crary, Techniques of The Observer.

40. See George A. Miller, "The Magical Number Seven, Plus or Minus Two: Some Limits on Our Capacity for Processing Information," Psychological Review 63, no. 2 (March 1956): 81-97; and Paul N. Edwards, The Closed World: Computers and the Politics of Discourse in Cold War America (Cambridge, MA, 1996), 175238. See also Gibson, "Motion Picture Testing and Research." See also the 1950s studies of air defense teams in Robert L. Chapman et al., "The Systems Research Laboratory's Air Defense Experiments,” Management Science 5, no. 3 (1959): 250-69 (Allen Newell was a member of this research project and a co-author on the report). See also J. C. R. Licklider's "Man-Computer Symbiosis," IRE Transactions on Human Factors in Electronics HFE-1 (March 1960): 4-11.

41. On Norbert Wiener, see his seminal co-authored text, Arturo Rosenblueth et al., "Behavior, Purpose, Teleology," Philosophy of Science 1 (January 1943): 1824; and Peter Galison, "The Ontology of the Enemy." On Shannon, see Claude E. Shannon, "Presentation of a Maze Solving Machine," in Cybernetics: Circular, Causal and Feedback Mechanisms in Biological and Social Systems, Transactions Eighth Conference, March 15-16, 1951, ed. M. Mead et al. (New York, 1952), 169-81; and Mindell, Between Human and Machine, 319-21. Regarding Margaret Mead, see Margaret Mead, "Cybernetics of Cybernetics," in Purposive Systems; Proceedings of the First Annual Symposium of the American Society for Cybernetics, ed. Heinz Von Foerster et al. (New York, 1969), 1-11. On Gregory Bateson, see Bernard Dionysius Geoghegan, "The Family as Machine: Film, Infrastructure, and Cybernetic Kinship in Suburban America," Grey Room 66 (Winter 2017): 70-101. On Roman Jakobson and Claude Lévi-Strauss, see Bernard Dionysius Geoghegan, "From Information Theory to French Theory: Jakobson, Lévi-Strauss, and the Cybernetic Apparatus," Critical Inquiry 38, no. 1 (2011): 96-126. For some of Harold Garfinkel's work along these lines, see Harold Garfinkel, Toward a Sociological Theory of Information, ed. Anne Warfield Rawls (Boulder, 2008).

42. I thank Nina Franz of Weimar and Berlin for bringing David Riesman's remarks (and their salience to a technical history of aerial defense) to my attention. See 
David Riesman, The Lonely Crowd (New Haven, 1989). On the radar type and radar research, see Sharon Ghamari-Tabrizi, "Cognitive and Perceptual Training in the Cold War Man-Machine System," in Joel Isaac and Duncan Bell, eds., Uncertain Empire: American History and the Idea of the Cold War (New York, 2012)— a remarkable text I thank Max Stadler for bringing to my attention. On the radar type, as such, see Helmut Lethen, Cool Conduct: The Culture of Distance in Weimar Germany, trans. Don Reneau (Berkeley, 2002), 187-94.

43. Riesman, The Lonely Crowd, 16.

44. Ibid., 25.

45. Ibid., 21.

46. Figures from "The Supersonic Shield," Time 64, no. 25 (December 20, 1954): $15-17$.

47. L. D. Attaway et al., "U. S. Active Air Defense, 1956-1960: Attrition and Target Damage Estimates," ASTIA Document Number ATI 210800, Project RAND Research Memorandum (US Air Force, January 5, 1954), ix-x.

48. "The Supersonic Shield," 16.

49. Hurst et al., "Retrospectives," 21.

50. Thomas Parke Hughes, Rescuing Prometheus (New York, 2000), 28.

51. Air Defense Systems Engineering Committee, "Air Defense System: ADSEC Final Report," October 24, 1950, MITRE Corporation Archives, Bedford, MA, quoted in ibid., 21.

52. Hurst et al., "Retrospectives," 22.

53. On the Cape Cod System, and for photographs of its direction center, see C. Robert Wieser, "The Cape Cod System," Annals of the History of Computing 5, no. 4 (October 1983): 362-69.

54. Stephen B. Johnson, The United States Air Force and the Culture of Innovation, 1945-1965 (Washington, DC, 2002), 149, 163. For a schematic overview of SAGE, see Robert R. Everett, Charles A. Zraket, and Herbert D. Bennington, "SAGE-A Data-Processing System for Air Defense," Annals of the History of Computing 5, no. 4 (October 1983): 330-39.

55. Theory of Operation of Display System for AN/FSQ-7 Combat Direction Center and AN/ FSQ-8 Combat Control Central, Volume I (Kingston, NY, 1958), 18-19, online at https://archive.org/details/bitsavers_ibmsage362ug58_40521123.

56. Ibid., 18.

57. Ibid., 20.

58. Bernd Ulmann, AN/FSQ-7: The Computer That Shaped the Cold War (Oldenbourg, 2014), 167.

59. In Your Defense: The SAGE System (The United States Air Force, ca. 1960), https:/ / www.youtube.com/watch?v=06drBN8nlWg. Courtesy of the Computer History Museum, accession number 102651595.

60. NORAD moved to this location in 1961.

61. On push-button warfare, see "Push-Button Defense," Newsweek, May 2, 1955, 27-28, 30; and on the iconic status of the push-button, see Rachel Plotnick, "At the Interface: The Case of the Electric Push Button, 1880-1923," Technology and Culture 53, no. 4 (2012): 815-45.

62. Regarding key innovations of the SAGE, see Edwards, The Closed World, 99-100.

63. Fred Turner, The Democratic Surround: Multimedia and American Liberalism from World War II to the Psychedelic Sixties (Chicago, 2013).

64. Licklider, "Man-Computer Symbiosis."

65. Sutherland, "Sketchpad," 111.

66. Charlie Gere, "Genealogy of the Computer Screen," 151. 
67. Pias, "The Game Player's Duty," 170-73.

68. On how software industries came to account for social factors within computing, see Nathan L. Ensmenger, The Computer Boys Take Over: Computers, Programmers, and the Politics of Technical Expertise (Cambridge, MA, 2010).

69. Claude Baum, The System Builders: The Story of SDC (Santa Monica, 1981).

70. Ibid., 4-5.

71. On crisis, catastrophe, and television, see the classic 1990 essay (featuring a helpful 2003 postscript) Mary Ann Doane, "Information, Crisis, Catastrophe," in New Media, Old Media: A History and Theory Reader, ed. Wendy Hui Kyong Chun and Thomas Keenan (New York, 2006), 251-64. For the extrapolation of those trends to digital media, see Wendy Hui Kyong Chun, "Crisis, Crisis, Crisis, or Sovereignty and Networks,” Theory, Culture EO Society 28, no. 6 (2011): 91-112. 